\title{
Passive, Active, or Co-Active? The Link Between Synchronous User Participation and Willingness to Pay for Premium Options
}

\author{
Simon Bründl \\ LMU Munich \\ bruendl@bwl.lmu.de
}

\begin{abstract}
Social media-enabled business models have transformed the content industry. To increase users, willingness to pay (WTP), many of today's content providers have changed from mere content provision towards offering social content experiences. Recent research has confirmed that users' participation activities, e.g. commenting on content, increase the WTP for social content services' premium options. So far, social content has been available predominantly ondemand, only allowing asynchronous user participation. Recently, social live content services emerged, which facilitate synchronous user participation and enable so-called co-active behavior. With this study, we conceptualize co-active behavior as the interplay between users while co-experiencing content together, and empirically show that co-active behavior has a stronger effect on WTP for premium options than the classic forms of passive and active behavior. Our work provides theoretical contributions on the WTP for social content as well as implications for the management of social content services.
\end{abstract}

\section{Introduction}

Social media-enabled business models have transformed the content industry, i.e. companies that provide mass media to consumers [34, 59]. Many of today's content providers have changed from mere provision of content towards "establishing contentrelated and IT-enabled social experiences" for their users, which are labelled as social content [52, p. 592]. To capture value, most social content services, e.g. Music-As-a-Service platforms such as Spotify, apply the freemium business model [73]. Services following the freemium model provide a free version of their offering with basic functionalities, while charging fees for additional premium features [2, 69]. However, the number of users converting from the free to the premium option still remains low $[10,38]$.
Recent research has shown that users' participation, e.g. liking or commenting on content, increases the probability to pay for a social content service's premium option [52, 76]. However, until recently, the social content that users experience has been available predominantly on-demand. Thus, users' participation has been limited to asynchronous participation behavior $[19,27]$, e.g. individuals consuming content or commenting on content independently from each other at different times [35]. Lately, a trend towards an increasing ephemerality of social media content has appeared [49, 54, 63]. Culmination of this trend is the emergence of simultaneously distributed and consumed social live content, e.g. in the form of social video live streams [25, 57]. Online services based on social live content enable the synchronous participation of users, e.g. simultaneous content consumption and real-time social interaction via chat $[11,12]$. Due to synchronous user participation, users are able to co-experience content together $[6,21]$. Therefore, online content services that allow users' synchronous participation are thought to offer higher levels of social interaction than services relying solely on asynchronous user participation [60]. Consequently, incumbent social media services such as Facebook and YouTube recently added social live content and synchronous participation features to their platforms [53].

While research has successfully explored the effect of users' asynchronous participation on their WTP, the role of synchronous participation behavior remains unclear. Classically, a user's participation activities can be aggregated into a dichotomy of user behavior [15]: On the one hand, passive behavior, which refers to users' content consumption activities. On the other hand, active behavior, which comprises users' content organization, community involvement, and community leadership activities [52]. Synchronous participation allows for an additional third type of user behavior: coactive behavior, which refers to the interplay between users while co-experiencing content together [8, 9]. While extant freemium literature acknowledges a link between social influences and WTP for premium 
options [4], the effect of users' actual co-active behavior on their WTP has not yet been examined. Consequently, we pose the following research question:

How does co-active behavior influence users' WTP for premium options on social content services?

To address this question, we adapt the 'ladder of participation' as a theoretical framework [52], expanding it to include co-active behavior of users. Our empirical analysis is based on a set of longitudinal data on individuals' usage behavior at Twitch, the marketleading online service for live content [53]. Subsequently, we apply a logit model to examine the link between the different levels of use behavior and the WTP for premium options.

The remainder of this paper is organized as follows: The next section discusses extant literature on the WTP for premium options of freemium services, followed by the development of our hypotheses. We then present an overview about our data collection process. Next, we specify a logit model, after which we present the results of our empirical analysis. Subsequently, we discuss our study's theoretical contributions and managerial implications. Finally, we close the paper with limitations of our work and highlight avenues for future research.

\section{WTP for freemium options}

The question why users pay for content is crucial for all online content services $[18,29,71,75]$. Over the last decade, the freemium model has established itself as the de-facto standard business model for content-driven online services $[24,64,68]$. A plethora of studies reflect this trend, examining users' WTP for a broad spectrum of freemium services, e.g. Music-as-a-Service platforms [20, 69], free-to-play games [24], or hedonic as well as professional social networks [26, 67].

Initially, research took a utilitarian perspective on users' WTP for premium options of freemium-based services $[20,26,67,69,70]$. Studies in that vein focus on perceptions of increased value and utility, which determine if users pay for premium options. For example, Doerr, Benlian, Vetter and Hess [20] showed that the premium option's price has the strongest effect on customers' perceived utility, which in turn increases the propensity to convert to a premium user. Similarly, Wagner and Hess [70] demonstrated that the perceived value of the premium version compared to its price is the key determinant of users' attitude towards premium options. Han and Windsor [26] identified that the perceived value of social connections acts as the primary predictor for users' WTP on hedonic social networks. Analogously, Vock, Dolen and Ruyter [67] found that the expected economic value is the most influential antecedent of WTP for premium options on professional social network sites. Contributing to the utilitarian perspective of previous studies, Wagner, Benlian and Hess [69] highlight the dominant role of the functional difference between free and premium options for users' WTP.

Recently, research has started to acknowledge the role of social aspects for users' WTP [51]. Prior literature taking a social stance on users' WTP falls into two main groupings. The first group of studies accounts for peer influences by third persons towards a user's WTP for premium options [4, 45, 67]. In this vein, Vock, Dolen and Ruyter [67] identified the salient role of users' social capital and their perceived sense of togetherness for the WTP for premium accounts on hedonic social network sites. Liu, Au and Choi [45] demonstrated that positive review ratings of other users influence an individual's WTP for premium versions of mobile apps. Bapna and Umyarov [4] found that gifting premium options to users increases their online friends' WTP.

The second group of studies focuses on the link between users' social participation and WTP for premium options $[3,52,76]$. Studies in this vein show that users' individual participation behavior (e.g. liking, commenting, or moderating) has a positive influence on their WTP. For example, Oestreicher-Singer and Zalmanson [52] demonstrated that voluntary user engagement follows a 'ladder of participation', where higher levels of social participation lead to a higher propensity to pay for the premium option. While user participation initially had only been examined as voluntary action, further research has shown that website-initiated social participation also fosters further participation, and in turn WTP for premium options [76]. Recently, Bapna, Ramaprasad and Umyarov [3] highlighted that the link between social participation and WTP is reciprocal, as paying for premium options increases users' social participation behavior and vice versa.

To sum up, recent research has shifted away from an initially utilitarian point of view and adopted a social approach to users' WTP, focusing either on the role of external social influences or user participation. However, extant literature has so far sustained a dichotomy of social influences and user participation experiences. We posit that in the context of live content, those two concepts should not be treated as dichotomous, but fused into a social-experiential perspective. Surprisingly, even though social content experiences by definition focus on users' shared experiences [52], the social-experiential aspects of user participation have so far been neglected by previous research [44]. 


\section{Hypotheses development}

We adapt Oestreicher-Singer and Zalmanson's theory of the 'ladder of participation' [52] as the theoretical foundation of our work. The ladder of participation draws on extant literature about offline and online communities, where several approaches highlight the path of gradually evolving user participation. Such approaches describe the rising social participation in 'communities of practice' [72], posit 'participation roles' [36], provide 'social technographic profiles' [42], or postulate a 'reader-to-leader' framework [55]. While the abovementioned approaches focus on different user roles, the ladder of participation synthesizes those roles according to their respective types of primary activities from a first-person perspective. Accordingly, the original ladder of participation comprises four levels of user participation (Table 1): First, content consumption, which refers to the user passively consuming content. Second, content organization, e.g. the user tags content or follows channels. Third, community involvement, e.g. the user comments on the actual content. Fourth, community leadership, which for example includes the user acting as a moderator.

Table 1. Overview of studies

\begin{tabular}{|c|c|c|}
\hline View Study & $\begin{array}{c}\text { Ladder of } \\
\text { Participation } \\
{[52]}\end{array}$ & $\begin{array}{c}\text { Ladder of } \\
\text { Activeness } \\
\text { (This Study) }\end{array}$ \\
\hline \multirow{4}{*}{$1^{\text {st }}$ person } & $\begin{array}{c}\text { Content } \\
\text { Consumption }\end{array}$ & $\begin{array}{c}\text { Passive } \\
\text { Behavior }\end{array}$ \\
\hline & $\begin{array}{c}\text { Content } \\
\text { Organization }\end{array}$ & \multirow{3}{*}{$\begin{array}{l}\text { Active } \\
\text { Behavior }\end{array}$} \\
\hline & $\begin{array}{l}\text { Community } \\
\text { Involvement }\end{array}$ & \\
\hline & $\begin{array}{l}\text { Community } \\
\text { Leadership }\end{array}$ & \\
\hline $\begin{array}{c}1^{\text {st }} \text { and } 2^{\text {nd }} \\
\text { person }\end{array}$ & - & $\begin{array}{l}\text { Co-Active } \\
\text { Behavior }\end{array}$ \\
\hline
\end{tabular}

Each of the four levels captures a higher degree of social participation. By drawing on organizational commitment theory [5, 47], the ladder of participation has shown that ascending levels of user participation have increasing effects on users' propensity to pay for premium options [52]. While the original ladder of participation synthesized the different levels of user participation according to activities, we posit an aggregation based on the degree of activeness of user behavior: passiveness, activeness, and co-activeness. As a first step, we therefore further synthesize the levels of the ladder of participation into passive and active behavior [15]. Active behavior comprises participation activities that afford active triggering by an individual and become visible to other consumers, e.g. community involvement. Passive behavior refers to user participation, which is only visible to the conducting individual, i.e. content consumption. In line with the theory of the ladder of participation, we hypothesize:

H1: Passive behavior is positively associated with the likelihood of subscribing to premium options.

H2: Active behavior is positively associated with the likelihood of subscribing to premium options.

H3: Active behavior has a stronger association with the decision to subscribe to premium options than will users' passive behavior.

Recent research posits that content should no longer be viewed solely as an information or experience good [43], but also as a social good [39]. Despite noting the social aspects of content experiences, the original ladder of participation takes a first-person perspective on user participation, focusing solely on the one-to-one interactions between the individual and the information system (IS) that enables the social content experience [32]. However, extant literature has for a long time highlighted the importance of social influences for individuals' behavior in general [1] and in particular in the context of IS usage $[65,66]$. Furthermore, studies have shown a positive effect of peer influence on further user participation, e.g. via social comparison with others $[16,56]$ or reactions from peers [13]. Recent research on freemium-based services linked social comparison mechanisms with users' WTP [4]. While extant freemium literature acknowledges the role of social influences per se, those factors are treated as external influences, which are not part of a user's actual participation experience. To account for social influences as an inherent aspect of user participation, we draw on the concept of co-experience to extend the classic ladder of participation by so-called co-active behavior.

The concept of co-experience originates from product design [6], being later adapted and reconceptualized by human-computer interaction research [44]. Co-experience per definition represents "the experience that users themselves create together in social interaction" [6, p. 1]. Axiom of the concept of coexperience is that experiencing is a social process [9]. Therefore, the focal proposition of co-experience research is that the experience of a product or service is a social phenomenon [8]. Accordingly, the physical or virtual behavior of others can influence one's own experience [21]. Furthermore, co-experience research posits that "interacting with other people is the basis of making sense of experiences" [9, p. 463]. Social interaction between users evolves around products or services, which therefore act as pivotal objects of co- 
experiences [7]. Thus, content-based online services may serve as channels for social interaction, fostering or inhibiting the occurrence of co-experiences [21]. In summary, the concept of co-experience posits the fusion of user experience and social interaction during product or service usage [7]. Accordingly, we propose to extend our understanding of user participation from an isolated first-person perspective towards the inclusion of an interactive second-person point of view $[6,44]$.

From an interactionist perspective, co-experiencing comprises three key elements: lifting an interaction up and reciprocating or rejecting the interaction $[8,9]$. Interaction occurs as a turn-based process between two parties [9]. Co-active behavior emerges when an individual actively lifts an interaction up to someone's attention and the other person reciprocates the interaction by reacting to the first person's behavior. Accordingly, we conceptualize co-active behavior as users' synchronous behavior, where one user initiates an interaction and a second user reacts to it. Such a process results in the first user receiving feedback through the second person's reaction [9]. Feedback to an activity acts as a motivational source [37]. Therefore, receiving feedback can increase users' enjoyment [14], participation [17, 40, 48], and attitude towards purchases [41]. Furthermore, feedback encourages users to continue with participation, which represents an expression of commitment [28, 31]. Prior research has shown that commitment increases users' WTP for premium options $[22,23,52]$. Taken together, we thus hypothesize:

H4: Co-active behavior is positively associated with the likelihood of subscribing to premium options.

H5: Co-active behavior has a stronger association with the decision to subscribe to premium options than will active behavior and passive behavior.

\section{Data collection}

To test our hypotheses, we collected actual usage data from Twitch, a freemium-based social media service. Twitch is the market-leading platform for social live streaming content, with a focus on gaming broadcasts [53]. Twitch's service allows its users to view user-generated video streams in real-time, while enabling the synchronous participation of users via textbased chats [11, 12, 57]. Twitch first attracted mainstream attention as Amazon took over the platform for $\$ 970$ million in 2014 [61]. In the same year Twitch already generated more internet traffic in the United States than Facebook and Amazon, making up 1.8\% of peak internet traffic [74]. For the year 2016 Twitch's users watched a total of 292 billion minutes of live content from 2.2 million unique broadcasters, while sending 14.2 billion chat messages [62].

Twitch's platform consists of a variety of useroperated micro-channels, which provide live content to consumers. These channels are self-contained, participatory online communities, where users informally socialize while watching the broadcast video live stream [25]. Each channel comprises a live video stream and a corresponding text-based chat. At the channel level, Twitch applies a freemium model which relies on two membership variants. Users can either select no-cost access and consume content on any channel (free option) or pay fixed monthly fees to subscribe to a channel (premium option). Accordingly, we differentiate between non-subscribers, who rely on free accounts, and subscribers, who purchased a channel subscription. Channel subscriptions provide the purchasing users with several additional features, e.g. no advertisements on the channel, new sets of emoticons for chatting, or a special badge in front of the user name.

At the channel level, user participation on Twitch comprises the following activities: a user can watch the channel (passive behavior, $1^{\text {st }}$ person perspective) or send publicly visible messages to the channel's chat (active behavior, $1^{\text {st }}$ person perspective). Chat messages can be either undirected or directed towards a certain user by putting '@username' in front of a message. Directed chat messages are visually highlighted to the addressed user, lifting a proposed interaction up to someone's attention [9]. In turn, the addressed user can either reject the interaction by disregarding the initial message or reciprocate by sending a response via a directed chat message towards the initiator of the interaction (co-active behavior, $1^{\text {st }}$ and $2^{\text {nd }}$ person perspective).

To collect data on the abovementioned user participation activities, we specially developed an event-driven software which utilizes Twitch's API to gather data on individuals' actual passive, active, and co-active behavior. Our data collection software continuously tracked user participation activities for a given set of Twitch channels and stored them in a database. We have collected usage data from 30 randomly chosen personal live streaming channels [33] over a time span of six weeks between April and May 2017. To obtain a complete history of users' participation activities, we confine our data set to users which registered their accounts after the start of our data collection. After filtering out bots and channel staff, our collected data set comprises the user participation activities of 153,820 users (unique to channel), including 152,634 non-subscribers and 1,186 subscribers. 


\section{Model specification}

Our methodological approach follows extant literature on user participation and WTP for premium options [52]. As users pay a fixed monthly fee to subscribe to a channel, the WTP to pay for the premium option can be operationalized as a binary variable [52]. Accordingly, we propose a binary-logit model to test our hypotheses. This approach allows us to assess the influence of passive, active, and co-active behavior on users' likelihood to pay for a subscription. Consequently, we specify the following model:

\section{$\mathrm{U}_{\mathrm{i}}$ (Subscriber)}

$$
\begin{aligned}
& =\alpha_{0}+\beta_{1} \text { PassiveBehavior }_{\mathrm{i}} \\
& +\sum_{\mathrm{k}=1}^{\mathrm{K}} \gamma_{\mathrm{k}} \text { ActiveBehavior }_{\mathrm{ki}} \\
& +\beta_{2} \text { CoActiveBehavior }_{\mathrm{i}} \\
& +\beta_{3} \text { SubscriberModeRatio }_{\mathrm{i}} \\
& +\varepsilon_{\mathrm{i}}
\end{aligned}
$$

As channels are self-contained online communities, our analysis unit are users unique to a channel $(i)$, i.e. if users participate in more than one channel their participation activities and subscriptions are recorded individually for each channel. Our binary dependent variable is 1 if user $i$ has subscribed to the channel and 0 if the user stayed with the free option as a nonsubscriber. Passive Behavior is measured by the minutes during which user $i$ watched the content of the channel. To measure Active Behavior we rely on the undirected chat messages by user $i$, i.e. chat messages which were not directed towards a certain user (Undirected Messages), and directed messages which are not followed by an answer towards user $i$ within ten minutes (Directed Messages). Co-Active Behavior is measured by the reciprocated interactions user $i$ experiences after sending directed chat messages. An interaction counts as reciprocated, if it is answered within a time frame of ten minutes after the initial directed message. As a channel's chat can be restricted to 'subscriber-only' mode, we additionally control for the time channels have been in subscriber-only mode. Subscriber Mode Ratio refers to the relative amount of time the channel, in which the data of user $i$ was recorded, has been in subscriber-only mode. For the observed channels of our data set the Subscriber Mode Ratio ranges between $0 \%$ and $31.58 \%$, with a mean of $7.46 \%$.

Recent research suggests that paying for premium options can increase users' participation [3]. To control for this effect, we differentiate between user participation activities before and after a user pays for a subscription. Accordingly, our logit model relies on a set of users consisting of non-subscribers and subscribers, where for the latter we only rely on their user participation activities before their subscription. As a result, the time span in which user participation activities were recorded differs between users. To account for that, we adjust Passive Behavior, Active Behavior, and Co-Active Behavior for each user $i$ by the number of recorded days for the respective user.

\section{Results}

For a comprehensive view on users' participation, we provide descriptive statistics of the analyzed data and examine potential differences in activity levels between non-subscribers and subscribers before we test our logit model. Table 2 presents descriptive statistics on users' participation behavior per day. We observed that the level of participation activity varies widely between users. For example, times per day spent on watching content ranges from 0.1 minutes to 23 hours with a standard deviation of 26 minutes. Furthermore, the numbers of sent and reciprocated chat messages a day per user are very low, as the majority of users are not participating via active or co-active behavior at all.

Table 2. Descriptive statistics

\begin{tabular}{|c|c|l|c|c|c|c|c|}
\hline Perspective & \multicolumn{1}{|c|}{ Type } & Measurement & Min & Max & Mean & Median & SD \\
\hline $1^{\text {st }}$ person & Passive Behavior & $\begin{array}{l}\text { Minutes watched } \\
\text { (per day) }\end{array}$ & .118 & 1386 & 7.246 & 1.069 & 26.98 \\
\hline \multirow{2}{*}{$1^{\text {st }}$ person } & Active Behavior & $\begin{array}{l}\text { Undirected chat messages } \\
\text { sent (per day) }\end{array}$ & .000 & 184.1 & .161 & .000 & 1.67 \\
\cline { 2 - 8 } & $\begin{array}{l}\text { Directed chat messages sent } \\
\text { (per day) }\end{array}$ & .000 & 22.11 & .006 & .000 & .165 \\
\hline $\begin{array}{c}1^{\text {st }} \text { and } 2^{\text {nd }} \\
\text { person }\end{array}$ & Co-Active Behavior & $\begin{array}{l}\text { Reciprocated interactions } \\
\text { (per day) }\end{array}$ & .000 & 22.09 & .0006 & .000 & .070 \\
\hline $\mathrm{N}=153,820$ &
\end{tabular}


In addition, we examined potential differences in activity levels between non-subscribers and subscribers. To check for significant differences, we calculated the ratios of user activities between those two groups and applied t-tests as well as Mann-Whitney U-tests as both populations follow a non-normal distribution [46]. On average, subscribers spent almost 10 times as much minutes watching live content $(\mathrm{p}<.001)$, sent 10 times as much undirected chat messages $(\mathrm{p}<.01)$, and 9 times as much directed chat messages $(\mathrm{p}<.001)$ than nonsubscribers. In addition, subscribers experienced 37 times as much reciprocated interactions than nonsubscribers $(\mathrm{p}<.001)$. Thus, subscribers showed significantly higher activity for all three types of user behavior than non-paying users. Table 3 presents the mean values of our independent variables for both user groups and the respective ratios.

Table 3. Activity levels of non-subscribers and subscribers

\begin{tabular}{|c|c|c|c|c|c|c|}
\hline Variable & Measurement & $\begin{array}{l}\text { Non-Subscriber } \\
\text { Mean }\end{array}$ & $\begin{array}{c}\text { Subscriber } \\
\text { Mean }\end{array}$ & Ratio & $\begin{array}{c}\text { T-Test } \\
\text { (P Value) }\end{array}$ & $\begin{array}{c}\text { U-Test } \\
\text { (P Value) }\end{array}$ \\
\hline $\begin{array}{l}\text { Passive } \\
\text { Behavior }\end{array}$ & $\begin{array}{l}\text { Minutes watched } \\
\text { (per day) }\end{array}$ & 6.7842 & 66.6868 & 9.817 & $.0000 * * *$ & $.0000 * * *$ \\
\hline \multirow{2}{*}{$\begin{array}{l}\text { Active } \\
\text { Behavior }\end{array}$} & $\begin{array}{l}\text { Undirected chat } \\
\text { messages sent (per day) }\end{array}$ & .1507 & 1.5860 & 10.520 & $.0000 * * *$ & $.0028 * *$ \\
\hline & $\begin{array}{l}\text { Directed chat messages } \\
\text { sent (per day) }\end{array}$ & .0062 & .0575 & 9.2538 & $.0056 * *$ & $.0000 * * *$ \\
\hline $\begin{array}{l}\text { Co-Active } \\
\text { Behavior }\end{array}$ & $\begin{array}{l}\text { Reciprocated } \\
\text { interactions (per day) }\end{array}$ & .0004 & .0177 & 37.326 & $.1429^{\mathrm{ns}}$ & $.0005^{* * *}$ \\
\hline
\end{tabular}

To assess the influence of user participation on the propensity to convert to premium, we estimate our specified logit model. Our model shows a significant log likelihood ratio, demonstrating that our proposed model performs better than the null model $(\mathrm{p}<.001)$. In addition, we computed Nagelkerke's pseudo $\mathrm{R}^{2}$, obtaining a value of 0.087 [50]. Such a value is in the norm, as low $\mathrm{R}^{2}$ values are characteristic for logit models and can't be compared to values from linear regression models [30]. Furthermore, we checked for multicollinearity between our independent variables by assessing variance inflation factors (VIF). VIF values range from 1.00 to 1.49 , indicating that multicollinearity is no issue for our model.

Table 4 presents the estimated effects of our logit model, sequentially adding blocks of independent variables to the estimation. Passive Behavior, measured in minutes watched per day, is associated with a significant increase in the propensity of subscribing to the channel, thus supporting H1. For each additional minute watched, a user's odds to subscribe to the channel increase by $1 \%$ (odds ratio $=1.010$ ). For Active Behavior we observed mixed results. Undirected Messages have a significant, positive association with the likelihood to subscribe to the channel. Each additional undirected message sent increases the odds to subscribe by $4 \%$ (odds ratio $=1.040$ ). However, Directed Messages have no significant effect on the propensity to subscribe $(\mathrm{p}>.05)$. Thus, we found only partial support for H2. As Active Behavior overall shows a stronger association with the subscription decision than Passive Behavior, we obtain support for $\mathrm{H} 3$. Furthermore, our results show that Co-Active Behavior, measured by the reciprocated interactions per day, is significantly associated with increasing the propensity to subscribe to the channel. Additional reciprocated chat messages increase the odds to subscribe by $22.2 \%$ (odds ratio $=1.222$ ). This finding suggests that co-active behavior plays a significant role for a user's subscription decision, thus supporting $\mathrm{H} 4$. We also observe a much stronger association to subscribe with Co-Active Behavior than Active Behavior, finding support for $\mathrm{H} 5$. Taken together, our results support the view that there exists a ladder of activeness for synchronous user participation in the context of social content. In addition, we also found a significant effect associated with Subscriber Mode Ratio. Each additional percent of time a channel is in subscriber-only mode increases the odds to subscribe by $3.6 \%$ (odds ratio $=1.036$ ) . 
Table 4. Binary Logistic Regression Model

\begin{tabular}{|c|c|c|c|c|}
\hline \multirow{4}{*}{ Independent Variables } & \multicolumn{4}{|c|}{ Model Estimates } \\
\hline & $\begin{array}{l}\text { Passive } \\
\text { Behavior }\end{array}$ & $\begin{array}{l}+ \text { Active } \\
\text { Behavior }\end{array}$ & $\begin{array}{c}+ \text { Co-Active } \\
\text { Behavior }\end{array}$ & $\begin{array}{c}\text { + Control Channel } \\
\text { Mode }\end{array}$ \\
\hline & B (S.E) & B (S.E) & B (S.E) & B (S.E) \\
\hline & $\operatorname{EXP}(B)$ & $\mathrm{EXP}(\mathrm{B})$ & $\operatorname{EXP}(B)$ & $\mathrm{EXP}(\mathrm{B})$ \\
\hline \multirow[t]{2}{*}{ Constant } & $\begin{array}{c}-5.0562 * * * \\
(.0316)\end{array}$ & $\begin{array}{c}-5.0629 * * * \\
(.0317)\end{array}$ & $\begin{array}{c}-5.0632 * * * \\
(.0317)\end{array}$ & $\begin{array}{c}-5.4098 * * * \\
(.0431)\end{array}$ \\
\hline & .0063 & .0063 & .0063 & .0044 \\
\hline \multirow[t]{2}{*}{ Minutes Watched } & $\begin{array}{l}.0112 * * * \\
(.0003)\end{array}$ & $\begin{array}{c}.0107 * * * \\
(.0003)\end{array}$ & $\begin{array}{c}.0107 * * * \\
(.0003)\end{array}$ & $\begin{array}{c}.0106 * * * \\
(.0003)\end{array}$ \\
\hline & 1.0112 & 1.0107 & 1.0107 & 1.0107 \\
\hline \multirow[t]{2}{*}{ Undirected Messages } & - & $\begin{array}{l}.0352 * * * \\
(.0061) \\
\end{array}$ & $\begin{array}{l}.0361 * * * \\
(.0061)\end{array}$ & $\begin{array}{l}.0399 * * * \\
(.0062)\end{array}$ \\
\hline & - & 1.0358 & 1.0367 & 1.0407 \\
\hline \multirow[t]{2}{*}{ Directed Messages } & - & $\begin{array}{l}-.0827^{\mathrm{ns}} \\
(.0764)\end{array}$ & $\begin{array}{l}-.1223^{\mathrm{ns}} \\
(.0828)\end{array}$ & $\begin{array}{l}-.1187^{\mathrm{ns}} \\
(.0818)\end{array}$ \\
\hline & - & .9206 & .8848 & .8880 \\
\hline \multirow[t]{2}{*}{ Reciprocated Interactions } & - & - & $\begin{array}{l}.2047^{*} \\
(.0919)\end{array}$ & $\begin{array}{l}.2012 * \\
(.0930)\end{array}$ \\
\hline & - & - & 1.2272 & 1.2229 \\
\hline \multirow[t]{2}{*}{ Subscriber Mode Ratio } & - & - & - & $\begin{array}{c}.0360 * * * \\
(.0023)\end{array}$ \\
\hline & - & - & - & 1.0366 \\
\hline Log Likelihood & -6485.893 & -6467.614 & -6465.953 & -6366.087 \\
\hline Nagelkerke's R-Square & .0698 & .0725 & .0728 & .0877 \\
\hline
\end{tabular}

\section{Theoretical contributions and managerial implications}

Our work provides contributions to theory on the WTP for social content experiences as well as implications for the management of social content services. From a theoretical point of view, our contribution is two-faceted. First, prior research on users' WTP has focused on the utilitarian or external social factors which motivate users to convert from free to premium options. In contrast, our study highlights the role of social-experiential aspects for users' WTP to pay for premium options. While extant literature has taken a predominantly isolated first-person perspective towards user participation $[52,76]$, we expand this perspective towards the inclusion of an interactive second-person point of view. Drawing on the idea of co-experiencing content, we introduce the concept of co-active behavior into IS research. We provide a first conceptualization of co-active behavior, elaborating how the interaction between users contributes to a user's likelihood to pay for premium options. By doing so, our study follows the call of Oestreicher-Singer and Zalmanson [52], who suggested that future research on the "local (person-toperson) social activity of consumers might provide interesting insights into the extent and nature of peer influence on the subscription decision" (p. 612).

Second, we provide an understanding about the link between synchronous user participation and WTP in the context of freemium-based social content services. Until now, previous studies on social content services have looked solely at users' asynchronous participation behavior. We fill this void by adapting the theory of the ladder of participation and empirically testing its applicability to synchronous user participation. Extant literature linking user participation and WTP for premium options focused on users' gradually-increasing involvement in a community [52]. In contrast, our conceptual approach highlights that, in the context of synchronous participation, the influence of user participation on WTP depends on the respective behavior's degree of activeness, i.e. passiveness, activeness, and co-activeness. With our study, we therefore followed a recent research call to examine how consumers' activeness can be monetized [64].

From a managerial perspective, our study provides insights into the viability of synchronous participation features as a means to increasing users' WTP to pay for premium options. Online services based on professionally created content, e.g. Spotify, successfully 
introduced the freemium model by relying on asynchronous participation features. In contrast, monetization of user-generated content via the freemium model has proved to be difficult $[43,58]$. Incumbent social media services such as YouTube, Facebook, or Instagram still rely primarily on advertisement-based business models to generate revenue from user-generated content [64]. For such services, the introduction of synchronous participation features might be the key to capture more value by monetizing social live content via the freemium model. Furthermore, our work allows social content providers to compare the effect of the different activity levels of synchronous participation on users' WTP, allowing them to design their services accordingly. As co-active behavior shows a higher influence on users' WTP than passive and active behavior, providers should no longer ask how to make their users participate more [52], but how to make them interact more reciprocally. Accordingly, social content providers should seek to introduce features which increase the possibilities and convenience for direct interactions between consumers. For example, directed messages could be placed prominently on top of the chat for the addressed user, who can then reciprocate the interaction via a quick response form right next to the initial message.

\section{Limitations, future research, and conclusion}

Our study has limitations which may offer avenues for future studies. First, while our analysis comprises a variety of micro-channels, all of those channels operate on a single platform, i.e. Twitch. For a more comprehensive understanding of synchronous user participation, it would prove useful to examine social live content services which have different thematic foci or feature sets than Twitch. Second, our analysis was limited to data which was available via Twitch's public API. Therefore, we had no access to demographic data such as users' age or gender, which might influence users' likelihood to pay for premium options. Therefore, future research should seek to combine actual usage data with additional information, e.g. by gathering selfreported survey data.

To conclude, our study took a social-experiential stance on user participation, expanding the ladder of participation towards the inclusion of an interactive second-person perspective and introducing the concept of co-active behavior. We see our work as a first step towards understanding the role of co-active behavior for the WTP for social content, hoping to spark further research interest on the participatory aspects of social content experiences.
Acknowledgment: We thank Dimiter Shopov and Sebastian Gavra for supporting the development of the data collection software.

\section{References}

[1] Ajzen, I., and Fishbein, M., Belief, Attitude, Intention and Behavior: An Introduction to Theory and Research, Reading, MA: Addison-Wesley, 1975.

[2] Anderson, C., Free: The Future of a Radical Price, New York: Hyperion, 2009.

[3] Bapna, R., Ramaprasad, J., and Umyarov, A., "Monetizing Freemium Communities: Does Paying for Premium Increase Social Engagement?", MIS Quarterly, forthcoming, pp. n/a.

[4] Bapna, R., and Umyarov, A., "Do Your Online Friends Make You Pay? A Randomized Field Experiment on Peer Influence in Online Social Networks", Management Science, 61(8), 2015, pp. 1902-1920.

[5] Bateman, P.J., Gray, P.H., and Butler, B.S., "The Impact of Community Commitment on Participation in Online Communities", Information Systems Research, 22(4), 2011, pp. 841-854.

[6] Battarbee, K., "Co-Experience: The Social User Experience", Proceedings of the 2003 Conference on Human Factors in Computing Systems, 2003. pp. 730-731.

[7] Battarbee, K., "Defining Co-Experience", Proceedings of the 2003 International Conference on Designing Pleasurable Products and Interfaces, 2003. pp. 109-113.

[8] Battarbee, K., and Koskinen, I., "Co-Experience: User Experience as Interaction", CoDesign, 1(1), 2005, pp. 5-18.

[9] Battarbee, K., and Koskinen, I., "Co-Experience: Product Experience as Social Interaction", Product Experience, 2008, pp. 461-476.

[10] Brandall, B., "Freemium Conversion Rate: Why Spotify Destroys Dropbox by 667\%", https://www.process.st/freemium-conversion-rate/, accessed 03/29/2017.

[11] Bründl, S., and Hess, T., "Why Do Users Broadcast? Examining Individual Motives and Social Capital on Social Live Streaming Platforms", Proceedings of the 20th Pacific Asia Conference on Information Systems (PACIS), 2016

[12] Bründl, S., Matt, C., and Hess, T., "Consumer Use of Social Live Streaming Services: The Influence of CoExperience and Effectance on Enjoyment", Proceedings of the 25th European Conference on Information Systems (ECIS), 2017.

[13] Burke, M., Joyce, E., Kim, T., Anand, V., and Kraut, R., "Introductions and Requests: Rhetorical Strategies That Elicit Response in Online Communities", in Steinfield, C., Pentland, B.T., Ackerman, M., and Contractor, N., eds.: Communities and Technologies 2007: Proceedings of the Third Communities and Technologies Conference, Michigan State University 2007, Springer London, London, 2007, pp. 21-39.

[14] Cheikh-Ammar, M., and Barki, H., "The Influence of Social Presence, Social Exchange and Feedback Features on Sns Continuous Use: The Facebook Context", Journal of Organizational and End User Computing (JOEUC), 28(2), 2016, pp. 33-52.

[15] Chen, A., Lu, Y., Chau, P.Y.K., and Gupta, S., "Classifying, Measuring, and Predicting Users' Overall Active 
Behavior on Social Networking Sites", Journal of Management Information Systems, 31(3), 2014, pp. 213-253. [16] Chen, Y., Harper, F.M., Konstan, J., and Li, S.X., "Social Comparisons and Contributions to Online Communities: A Field Experiment on Movielens", American Economic Review, 100(4), 2010, pp. 1358-1398.

[17] Cheng, J., Danescu-Niculescu-Mizil, C., and Leskovec, J., "How Community Feedback Shapes User Behavior", Proceedings of the 8th International Conference on Weblogs and Social Media (ICWSM), 2014.

[18] Choi, J., Lee, S.M., and Soriano, D.R., "An Empirical Study of User Acceptance of Fee-Based Online Content", Journal of Computer Information Systems, 49(3), 2009, pp. 60-70.

[19] Daugherty, T., Eastin, M.S., and Bright, L., "Exploring Consumer Motivations for Creating User-Generated Content", Journal of Interactive Advertising, 8(2), 2008, pp. 16-25.

[20] Doerr, J., Benlian, A., Vetter, J., and Hess, T., "Pricing of Content Services-an Empirical Investigation of Music as a Service": Sustainable E-Business Management, Springer, 2010, pp. 13-24.

[21] Forlizzi, J., and Battarbee, K., "Understanding Experience in Interactive Systems", Proceedings of the 5th Conference on Designing Interactive Systems: Processes, Practices, Methods, and Techniques, 2004. pp. 261-268.

[22] Fullerton, G., "When Does Commitment Lead to Loyalty?", Journal of Service Research, 5(4), 2003, pp. 333344.

[23] Fullerton, G., "The Service Quality-Loyalty Relationship in Retail Services: Does Commitment Matter?", Journal of Retailing and Consumer Services, 12(2), 2005, pp. 99-111.

[24] Hamari, J., Hanner, N., and Koivisto, J., "Service Quality Explains Why People Use Freemium Services but Not If They Go Premium: An Empirical Study in Free-to-Play Games", International Journal of Information Management, 37(1, Part A), 2017, pp. 1449-1459.

[25] Hamilton, W.A., Garretson, O., and Kerne, A., "Streaming on Twitch: Fostering Participatory Communities of Play within Live Mixed Media", Proceedings of the 2014 Conference on Human Factors in Computing Systems, 2014. pp. 1315-1324.

[26] Han, B., and Windsor, J., "An Investigation on the User's Willingness to Pay on Hedonic Social Network Sites", Proceedings of the 18th Americas Conference on Information Systems (AMCIS), 2012.

[27] Haridakis, P., and Hanson, G., "Social Interaction and CoViewing with Youtube: Blending Mass Communication Reception and Social Connection", Journal of Broadcasting \& Electronic Media, 53(2), 2009, pp. 317-335.

[28] Hong, Y., Gu, B., Burtch, G., Huang, N., Liang, C., Wang, K., Fu, D., and Yang, B., "Effectiveness of Performance Feedback in Stimulating User-Generated Content", Proceedings of the Thirty Seventh International Conference on Information Systems, 2016.

[29] Horng, S.-M., "A Study of the Factors Influencing Users' Decisions to Pay for Web 2.0 Subscription Services", Total Quality Management \& Business Excellence, 23(7-8), 2012, pp. 891-912.

[30] Hosmer Jr, D.W., Lemeshow, S., and Sturdivant, R.X., Applied Logistic Regression, John Wiley \& Sons, 2013.
[31] Joyce, E., and Kraut, R.E., "Predicting Continued Participation in Newsgroups", Journal of Computer-Mediated Communication, 11(3), 2006, pp. 723-747.

[32] Junglas, I., Goel, L., Abraham, C., and Ives, B., "The Social Component of Information Systems-How Sociability Contributes to Technology Acceptance", Journal of the Association for Information Systems, 14(10), 2013, pp. 585616.

[33] Karhulahti, V.-M., "Prank, Troll, Gross and Gore: Performance Issues in Esport Live-Streaming", Proceedings of the 1st International Joint Conference of DiGRA and FDG, 2016. pp. 1-6.

[34] Ketonen-Oksi, S., Jussila, J.J., and Kärkkäinen, H., "Social Media Based Value Creation and Business Models", Industrial Management \& Data Systems, 116(8), 2016, pp. $1820-1838$

[35] Khan, M.L., "Understanding Motives for User Consumption and Participation on Youtube: A Uses and Gratifications Perspective", Proceedings of the 12th Annual IADIS International Conference on the WWW/Internet (ICWI), 2013.

[36] Kim, A.J., Community Building on the Web: Secret Strategies for Successful Online Communities, AddisonWesley Longman Publishing Co., Inc., Berkeley, 2000.

[37] Kluger, A.N., and Denisi, A., The Effects of Feedback Interventions on Performance: A Historical Review, a MetaAnalysis, and a Preliminary Feedback Intervention Theory, American Psychological Association, 1996.

[38] Koch, O.F., and Benlian, A., "The Effect of Free Sampling Strategies on Freemium Conversion Rates", Electronic Markets, 27(1), 2017, pp. 67-76.

[39] Krastel, Z., Bassellier, G., and Ramaprasad, J., "Music Is Social: From Online Social Features to Online Social Connectedness", Proceedings of the 36th International Conference on Information Systems, 2015.

[40] Lampe, C., and Johnston, E., "Follow the (Slash) Dot: Effects of Feedback on New Members in an Online Community", Proceedings of the 2005 International ACM SIGGROUP Conference on Supporting Group Work, 2005, pp. 11-20.

[41] Lesma, V.R.B., and Okada, H., "Influence of Feedback from Sns Members on Consumer Behavior in Electronic Commerce", Proceedings of the 2012 International Conference on Advances in Social Networks Analysis and Mining, 2012. pp. 1189-1193.

[42] Li, C., and Bernoff, J., Groundswell: Winning in a World Transformed by Social Technologies, Harvard Business Press, Boston, 2011.

[43] Li, Z., and Cheng, Y., "From Free to Fee: Exploring the Antecedents of Consumer Intention to Switch to Paid Online Content", Journal of Electronic Commerce Research, 15(4), 2014, pp. 281.

[44] Lim, S., Cha, S.Y., Park, C., Lee, I., and Kim, J., "Getting Closer and Experiencing Together: Antecedents and Consequences of Psychological Distance in Social MediaEnhanced Real-Time Streaming Video", Computers in Human Behavior, 28(4), 2012, pp. 1365-1378.

[45] Liu, C.Z., Au, Y.A., and Choi, H.S., "Effects of Freemium Strategy in the Mobile App Market: An Empirical Study of Google Play", Journal of Management Information Systems, 31(3), 2014, pp. 326-354. 
[46] Mann, H.B., and Whitney, D.R., "On a Test of Whether One of Two Random Variables Is Stochastically Larger Than the Other", The Annals of Mathematical Statistics, 1947, pp. 50-60.

[47] Meyer, J.P., and Allen, N.J., "A Three-Component Conceptualization of Organizational Commitment", Human Resource Management Review, 1(1), 1991, pp. 61-89.

[48] Moon, J.Y., and Sproull, L.S., "The Role of Feedback in Managing the Internet-Based Volunteer Work Force", Information Systems Research, 19(4), 2008, pp. 494-515.

[49] Morlok, T., Schneider, K., Matt, C., and Hess, T., "Snap. Share.(Don't) Care? Ephemerality, Privacy Concerns, and the Use of Ephemeral Social Network Sites", Proceedings of the 23rd Americas Conference on Information Systems (AMCIS), 2017.

[50] Nagelkerke, N.J., "A Note on a General Definition of the Coefficient of Determination", Biometrika, 78(3), 1991, pp. 691-692.

[51] Niemand, T., Tischer, S., Fritzsche, T., and Kraus, S., "The Freemium Effect: Why Consumers Perceive More Value with Free Than with Premium Offers", Proceedings of the 36th International Conference on Information Systems (ICIS), 2015.

[52] Oestreicher-Singer, G., and Zalmanson, L., "Content or Community? A Digital Business Strategy for Content Providers in the Social Age", MIS Quarterly, 37(2), 2013, pp. 591-616.

[53] Pires, K., and Simon, G., "Youtube Live and Twitch: A Tour of User-Generated Live Streaming Systems", Proceedings of the 6th ACM Multimedia Systems Conference, 2015, pp. 225-230.

[54] Piwek, L., and Joinson, A., "“What Do They Snapchat About?" Patterns of Use in Time-Limited Instant Messaging Service", Computers in Human Behavior, 54(C), 2016, pp. 358-367.

[55] Preece, J., and Shneiderman, B., "The Reader-to-Leader Framework: Motivating Technology-Mediated Social Participation", AIS Transactions on Human-Computer Interaction, 1(1), 2009, pp. 13-32.

[56] Ren, Y., Harper, F.M., Drenner, S., Terveen, L., Kiesler, S., Riedl, J., and Kraut, R.E., "Building Member Attachment in Online Communities: Applying Theories of Group Identity and Interpersonal Bonds", MIS Quarterly, 36(3), 2012, pp. 841-864.

[57] Scheibe, K., Fietkiewicz, K.J., and Stock, W.G., "Information Behavior on Social Live Streaming Services", Journal of Information Science Theory \& Practice, 4(2), 2016, pp. 6-20.

[58] Schreiner, M., and Hess, T., "On the Willingness to Pay for Privacy as a Freemium Model: First Empirical Evidence", Proceedings of the 23rd European Conference on Information Systems (ECIS), 2013.

[59] Shan, L.M., Sutanto, J., Kankanhalli, A., and Tan, B.C., "Virtual Community Models in Relation to E-Business Models", in Lee, I., ed.: Electronic Business: Concepts, Methodologies, Tools, and Applications, PA: IGI Global, Hershey, 2005, pp. 669-677.

[60] Tang, J.C., Venolia, G., and Inkpen, K.M., "Meerkat and Periscope: I Stream, You Stream, Apps Stream for Live
Streams", Proceedings of the 2016 Conference on Human Factors in Computing Systems, 2016. pp. 4770-4780.

[61] Time, "Amazon to Buy Video Game Live-Streaming Site Twitch for $\$ 970$ Million", http://time.com/3176912/amazontwitch-970-million/, accessed 03/29/2017.

[62] Twitch, "Year in Review: 2016", https://www.twitch.tv/year/2016/, accessed 03/20/2017.

[63] Utz, S., Muscanell, N., and Khalid, C., "Snapchat Elicits More Jealousy Than Facebook: A Comparison of Snapchat and Facebook Use", Cyberpsychology, Behavior, and Social Networking, 18(3), 2015, pp. 141-146.

[64] Veit, D., Clemons, E., Benlian, A., Buxmann, P., Hess, T., Kundisch, D., Leimeister, J.M., Loos, P., and Spann, M., "Business Models", Business \& Information Systems Engineering, 6(1), 2014, pp. 45-53.

[65] Venkatesh, V., and Davis, F.D., "A Theoretical Extension of the Technology Acceptance Model: Four Longitudinal Field Studies", Management Science, 46(2), 2000, pp. 186204.

[66] Venkatesh, V., Morris, M.G., Davis, G.B., and Davis, F.D., "User Acceptance of Information Technology: Toward a Unified View", MIS Quarterly, 27(3), 2003, pp. 425-478.

[67] Vock, M., Dolen, W.V., and Ruyter, K.D., "Understanding Willingness to Pay for Social Network Sites", Journal of Service Research, 16(3), 2013, pp. 311-325.

[68] Voigt, D.-W.-I.S., and Hinz, O., "Making Digital Freemium Business Models a Success: Predicting Customers' Lifetime Value Via Initial Purchase Information", Business \& Information Systems Engineering, 58(2), 2016, pp. 107-118. [69] Wagner, T.M., Benlian, A., and Hess, T., "Converting Freemium Customers from Free to Premium - the Role of the Perceived Premium Fit in the Case of Music as a Service", Electronic Markets, 24(4), 2014, pp. 259-268.

[70] Wagner, T.M., and Hess, T., "What Drives Users to Pay for Freemium Services? Examining People's Willingness to Pay for Music Services", Proceedings of the 19th Americas Conference on Information Systems, 2013.

[71] Wang, C.L., Zhang, Y., Ye, L.R., and Nguyen, D.-D., "Subscription to Fee-Based Online Services: What Makes Consumer Pay for Online Content?", Journal of Electronic Commerce Research, 6(4), 2005, pp. 304-311.

[72] Wenger, E., Communities of Practice: Learning, Meaning, and Identity Cambridge University Press, Cambridge UK, 1998.

[73] Wilson, F., "The Freemium Business Model", http://avc.com/2006/03/the_freemium_bu/, accessed 03/03/2017.

[74] WSJ, "Apple Quietly Builds New Networks", https://www.wsj.com/news/articles/SB100014240527023048 51104579361201655365302, accessed 2017/03/22.

[75] Ye, L.R., Zhang, Y., Nguyen, D.-D., and Chiu, J., "FeeBased Online Services: Exploring Consumers' Willingness to Pay", Journal of International Technology and Information Management, 13(1), 2004, pp. 133-141.

[76] Zalmanson, L., and Oestreicher-Singer, G., "'Your Action Is Needed': The Effect of Website-Initiated Participation on User Contributions to Content Websites", Proceedings of the 36th International Conference on Information Systems, 2015. 